\title{
Classificação da língua dos Cinta-Larga
}

\author{
Aryon Dall'Igna Rodrigues
}

Da mesma informante de que se serviu o Pe. Adalberto Holanda Pereira para obter o vocabulário dos índios Cinta-Larga que ora publica nesta revista ${ }^{1}$, colheu a Dra. Sarah Gudschinsky, linguista do Summer Institute of Linguistics e da Universidade de Brasília, em dezembro de 1962, uma lista de 39 palavras. Mais não pôde registrar a nossa colega, porque não lhe foi possível demorar-se em Utiariti, onde se encontrava a informante, e porque esta se achava então seriamente doente. Aquelas 39 palavras permitiam-nos supor que se tratava de uma língua Tupí, mas não autorizavam qualquer pronunciamento mais detalhado. Agora, reunindo as duas listas, temos um total de 143 formas diferentes, que permitem verificar que a língua dos Cinta-Larga é muito próxima do Mondé (ou Sanamaikã ou Salamãi), do qual diverge, provavelmente, em nível apenas dialetal. Pertence, assim, à família linguística Mondé, que é uma das sete famílias que, ao lado da Tupí-Guaraní, compõem o tronco linguístico Tupíi ${ }^{2}$. Outras línguas da família Mondé são o Digüt e o Aruá.

Apresentamos aqui as evidências do estreito parentesco entre o CintaLarga, o Mondé e o Digüt ${ }^{3}$, servindo-nos da lista de palavras Mondé colhida e publicada por Hanke ${ }^{4}$ e do vocabulário Digüt de Schultz 5 . Das formas do Cinta-Larga destacamos o elemento -mã?ã ou -ã?ã, que acompanha quase

1. N. do E.: Referência a texto publicado no vol. XIV, da Revista de Antropologia (1966).

2. Vide Rodrigues, "Classificação do tronco linguístico tupi", Revista de Antropologia, vol. XII, pp. 99-104.

3. Os Mondé foram encontrados por Hanke no alto Guaporé, pouco antes de 1950; ela informa, entretanto, que suas aldeias, que ela não visitou, ficariam no alto Machado ou Ji-Paraná; Lévi-Strauss visitou uma aldeia no Pimenta-Bueno, em 1938 (v. Tristes trópicos, São Paulo, 1957, pp. 351 ss.). Schultz achou os Digüt na altura do igarapé de Lourdes, afluente direito do alto Machado. 
todas as expressões colhidas por Pereira e que aparece como - $m a$ ou $-a$ no registro de Gudschinsky, mas não ocorre no Mondé; destacamos também o prefixo $p a-$ ou $p$-, provavelmente um prefixo pessoal que acompanha os nomes de partes do corpo, assim como, no Mondé e no Digüt, separamos o prefixo pessoal un-, on- "meu". Substituímos as consoantes sonoras registradas por Hanke após o prefixo un- pelas surdas correspondentes. Aproximamos as transcrições de Hanke, Schultz e Gudschinsky à de Pereira, adaptando-as assim às possibilidades desta revista; mas escrevemos $\tilde{n}$ em lugar de $n h$.

A seguir damos as palavras do Cinta-Larga, para as quais se encontram correspondências no Mondé (M) e no Digüt (D), comparadas com as formas destas duas línguas. A abreviatura $\mathrm{G}$ distingue as palavras colhidas por $\mathrm{Gu}-$ dschinsky.

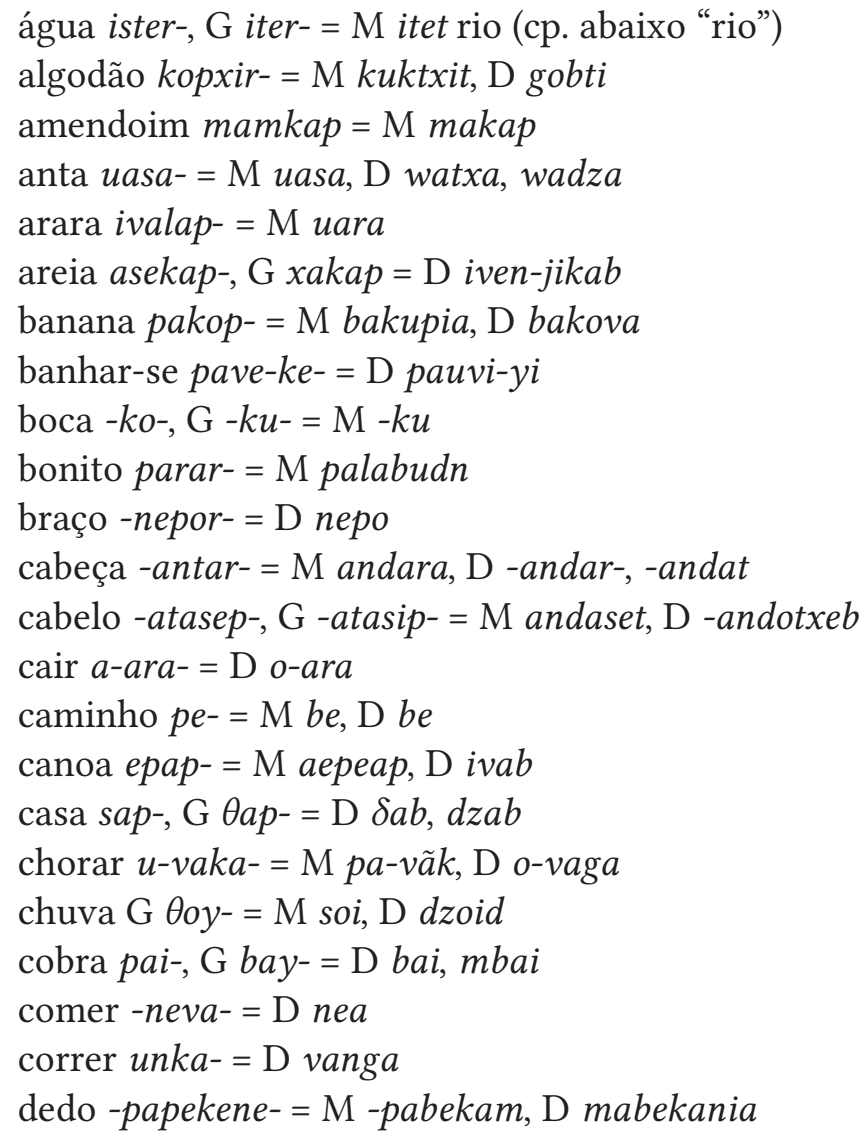

4. Wanda Hanke, "Breves notas sobre os índios Mondé e o seu idioma”, Dusenia (Curitiba), vol. I, 1950, pp. 215-228.

5. Harald Schultz, "Vocábulos Urukú e Digüt", Journal de la Société des Américanistes (Paris), n. s., vol. XLIV, 1955, pp. 81-97. 
dente $\mathrm{G}-\tilde{n} i \tilde{n}-=\mathrm{D}$ nin

dormir -kere- $=\mathrm{M}-$ ket, $\mathrm{D}$-kerea

espinho vape- $=\mathrm{M}$ vuape, $\mathrm{D}$ oope

eu un $^{-}=\mathrm{M}$ ono

faca, machado tape- = M tabe, $\mathrm{D}$ tabe-, dabe

ferida kain- = D -kain

flecha $x a p-=\mathrm{M} j a b, \mathrm{D}$ djob, djop

fogo bokai, G pukãy = M kai, D pokain

folha basep-, G paxip- = M baset, D badzeb

fumaça $G$ vanin- = M vanim

gavião $i k o l m-=\mathrm{M} i k u(n) m$

homem oi-, G uy- = M oi

irmã umpar- = D ombara

jacaré $v a v u-=\mathrm{M} v a u, \mathrm{D} v a v u$

lavar G pixa- $=$ D pitxa

língua $-k u k a p-=\mathrm{D}$ gokab

lua kati- = M gati, D gati

macaco G basai- = M masãi, D badzaid-peb uacari, madzaid-kora parauacu

mãe kaie- = D gay, gaya

mandioca sepoi-, G xipuy- = D djiboya

mão -pape- = M -pabe, $\mathrm{D}$ babe

matar saka- = M tsaka, D dzaga-

milho maek-, G m?ek- = M maik (impresso waik), D mainkin

mulher uansed-, G baser- = M wanzet, $\mathrm{D}$ manzeya

noite bixa-, G mixay- = M bitxam-mi

olhar osi-kene- $=\mathrm{D}$-kine- $a$

olho -sakep-, G -xakip- = M -txakap, D -dyakab

onça neko-, G neku- = M meku, D neko

orelha G-nepiap- = D -nepiab

orifício do lábio inferior -pepoma- $=\mathrm{M}$-pepoã

panela busap-, G botap- = D bodzab

pássaro intha- $=\mathrm{M}$ inda

pau, mato ep-, G ip- = M iva, D iva, iv

pé $-p i-=\mathrm{M}-p i a, \mathrm{D} b i$

pedra isxa-, Gixa- = M xaa, D idja

peixe purip-, G bulip- = M murip, D borivei

pele $\mathrm{G}$-xirik- = D zerek

perna -upe- = M -upe coxa

piolho kir- $=\mathrm{M}$ gib, $\mathrm{D}$ dyid

rabo $\mathrm{G}$ sapu- = M txapoo

rede $i \tilde{n} a^{-}=\mathrm{M}$ in, $\mathrm{D}$ ínea 


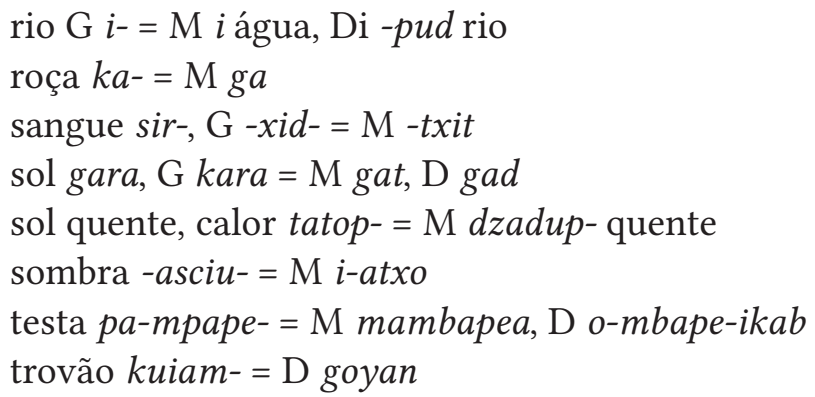

Como ainda não houve oportunidade de publicar evidências das afinidades da família Mondé com o tronco Tupí, apresentamos aqui uma série de morfemas do Cinta-Larga cotejados com as formas correspondentes do Tupinambá (família Tupí-Guaraní) e com as formas reconstruídas do Proto-Tupí':

Cinta-Larga
pak acordar
pav morrer
pe caminho
pi pé
pati pesado
pa-pe mão (mão-superfície)
pa-pe mão (mão-superfície)
pay cobra
api, ami nariz
nin fumaça
ka roça
kar sol
ker dormir
ip pau
ar cair
evir mel
ini- rede
djay, ñiñ dente
-ati- dor

\begin{tabular}{|c|c|}
\hline Tupinambá & Proto-Tupí \\
\hline pak & *pak \\
\hline$p a b$ & ${ }^{*} p a b$ \\
\hline pe & *pe \\
\hline$p \ddot{i}$ & * $p i$ \\
\hline posïy & * potsïy \\
\hline po mão & ${ }^{*} p o$ \\
\hline pe superfície & *pe \\
\hline moy & *mpoy \\
\hline ap̈̈ny & *ãpïy \\
\hline tin & ${ }^{*}$ tin \\
\hline ko & ${ }^{*} k o$ \\
\hline kwar & ${ }^{*} k w a r$ \\
\hline ker & ${ }^{*} c^{\prime} e r$ \\
\hline Tib & ${ }^{*} k^{\prime} \ddot{\imath} b$ \\
\hline Par & ${ }^{*} k^{\prime} a r$ \\
\hline eir & *ewïr \\
\hline inin & *ẽri \\
\hline$\tilde{a} y$ & *(y) $\tilde{a} y$ \\
\hline asï doído & ${ }^{*} a t s i$ \\
\hline
\end{tabular}

É possível que o Cinta-Larga pakop-, assim como o Mondé bakup-ia e o Digüt bakov-a, que correspondem ao Tupinambá pakob, não se devam a uma origem comum Proto-Tupí, mas sejam empréstimo de alguma língua da

6. Para algumas destas formas, vide Hanke, Swadesh e Rodrigues, "Notas de fonologiaMekens”, Miscellanea Paul Rivet Octogenario Dicata, México, 1958, vol. II, pp. 187-217. 
família Tupí-Guaraní. Determinar se temos de fato um caso de empréstimo ou de origem comum Proto-Tupí é problema ligado ao da difusão da banana, de grande importância tanto para o linguista como para o etnólogo. Ainda não há, entretanto, elementos suficientes para a apreciação linguística do problema. 